\title{
Classification of bifid mandibular canals using cone beam computed tomography
}

\section{Gisele Maria Correr \\ Daiana Iwanko \\ Denise Piotto Leonardi \\ Lucienne Miranda Ulbrich \\ Melissa Rodrigues de Araújo \\ Tatiana Miranda Deliberador}

Mestrado Profissional em Odontologia Clínica, Universidade Positivo, Curitiba, PR, Brazil.

Declaration of Interests: The authors certify that they have no commercial or associative interest that represents a conflict of interest in connection with the manuscript.

\section{Corresponding author:}

Gisele Maria Correr

E-mail: giselenolasco@up.com.br

hitp://dx.doi.org/10.1590/S1806-83242013000600011

Submitted: May 20, 2013

Accepted for publication: Jul 31, 2013

Last revision: Aug 12, 2013
Abstract: The objective of this study was to classify the morphology of bifid mandibular canals and to evaluate their relationship with the roots of third molars, using cone beam computed tomography (CBCT) scans. The CBCT scans of 75 patients were analyzed and the bifurcations were classified according to Langlais et al. (1985). The relationship of bifurcation and third molars was established according to the following classification: class A - uninvolved, class B - close relationship, class C - intimate relationship and class D - absence of third molars. Data were submitted to descriptive statistics, and the results indicated that the patients' mean age was $48.2( \pm 13.2)$ years. Unilateral bifurcation (Type 1$)$ was the most frequent type (72.6\%), followed by unilateral Type 2 (19.3\%). Class D was the most frequent $(57.33 \%)$, followed by class C $(21.33 \%)$, class B $(13.33 \%)$ and class A (8\%). It could be concluded that most cases presented unilateral bifid mandibular canals extending to the third molar or adjacent regions, and when present, the roots seemed to be a continuation of the bifid mandibular canal.

Descriptors: Mandibular Nerve; Anatomy; Cone-Beam Computed Tomography.

\section{Introduction}

The mandibular canal is referred to as a bilateral single structure; however, reports in the literature clearly show the presence of a second or even a third accessory nerve branch. ${ }^{1-4}$ Greater knowledge of the mandibular canal anatomy may help in performing different procedures in the dental clinic. Because of the proximity of the inferior alveolar nerve to the mandibular canal, there are procedures that offer great risk of nerve injury, such as lower third molar extractions, placement of dental implants, orthognathic surgery, and fixation of mandibular fractures. ${ }^{5,6}$

Because many professionals are unaware of the anatomical variations of the mandibular canal, they often go unrecognized even though they may be recorded in panoramic radiographs. ${ }^{7}$

Various types of bifid mandibular canals have been described and classified in the literature according to anatomical location and configuration, by using panoramic radiographs. ${ }^{8-11}$ However, few studies have used computerized tomography for this purpose. ${ }^{12-15}$ According to Rouas et al., ${ }^{12}$ panoramic radiographs can only suggest the presence of bifid mandibular canals, but cannot confirm them. According to the authors, 
only a tridimensional image exam, such as the cone beam computed tomography (CBCT), can show the presence and morphology of the bifurcation path of the mandibular canal precisely.

Thus, the aim of this study was to classify the morphology of bifid mandibular canals and evaluate their relationship with the roots of third molars, using CBCT scans of patients with this anatomical variation.

\section{Methodology}

This retrospective study was carried out after approval by the Institutional Review Board (protocol \# 114/11).

Seventy-five CBCT scans previously diagnosed with bifurcation of the mandibular canal were obtained from the database of two private dental radiology clinics located in the cities of São Paulo, SP, and Joinville, SC, Brazil.

All exams previously diagnosed with bifurcation of the mandibular canal were taken from the database, and were selected by a radiologist with over 10 years of experience. The examinations were performed for various reasons (implant surgery, mandibular fractures, etc.). All patients consented to using CBCT images for research purposes. The scans used in this study corresponded to a sample of individuals of both genders and different age groups. The study was conducted between May 2007 and May 2011. All exams were obtained using the same CBCT i-CAT (Imaging Sciences International, Heatfield, USA), with technical parameters of $120 \mathrm{kVp}, 5 \mathrm{~mA}$, $0.25 \mathrm{~mm}$ voxel and $40 \mathrm{~s}$ acquisition. The images were analyzed by XoranCAT tomography software (version 3.1.62; Xoran Technologies, Ann Arbor, USA).

The CT images obtained were analyzed twice by the same calibrated examiner, with an interval of two weeks (intra-examiner Kappa test $=0.89$ ). The analysis was performed in a quiet environment with adequate lighting and was evaluated in three spatial planes (axial, coronal and sagittal), and in transaxial or oblique slices formed from an outline of the axial cut and subsequent transversal cuts, always following the mandibular canal path. Vertical inclination of the axial image made it possible to keep the sagittal cut more parallel to the long axis of the mandibular canal, and represented an important resource for determining the path practically in its entirety. The sagittal cut allowed the best observation of the mandibular canal bifurcation.

Image density and contrast were adjusted digitally for easy viewing. Images were classified by gender and age, morphology of the bifurcation and relationship of the bifid mandibular canal to third molar roots. Afterwards, the mandibular canal course was observed, and the bifurcation was classified according to Langlais et al. ${ }^{9}$ (Table 1).

A classification was assigned to each image for the purpose of evaluating the relationship of the bifid mandibular canal and the roots of third molars, as follows:

a. no involvement of the bifid mandibular canal with the third molar;

b. close relationship of the third molar root with the mandibular canal bifurcation (the bifurcation is close to the third molar root but does not touch it),

c. intimate relationship between the third molar

Table 1 - Mandibular canal bifurcation according to Langlais et al. ${ }^{9}$

\begin{tabular}{|c|c|}
\hline $\begin{array}{c}\text { Type of } \\
\text { bifurcation }\end{array}$ & Description \\
\hline Type 1 & $\begin{array}{l}\text { - Unilateral bifurcation extending to and border- } \\
\text { ing (surrounding area) the region of the third } \\
\text { molar (1U) } \\
\text { - Bilateral bifurcation extending to and bordering } \\
\text { (surrounding area) (1B) the region of the third } \\
\text { molar }\end{array}$ \\
\hline \multirow{2}{*}{ Type 2} & $\begin{array}{l}\text { - Unilateral bifurcation extending along the main } \\
\text { canal and then coming together in the mandibu- } \\
\text { lar rami ( } 2 \cup R) \\
\text { - Unilateral bifurcation extending along the main } \\
\text { canal and then coming together in the mandibu- } \\
\text { lar body ( } 2 \cup C)\end{array}$ \\
\hline & $\begin{array}{l}\text { - Bilateral bifurcation extending along the main } \\
\text { canal and then coming together in the mandibu- } \\
\text { lar rami ( } 2 B R) \\
\text { - Bilateral bifurcation extending along the main } \\
\text { canal and then coming together in the mandibu- } \\
\text { lar body ( } 2 B C)\end{array}$ \\
\hline Type 3 & Combination of the first two categories (Types $1 \& 2$ ) \\
\hline Type 4 & $\begin{array}{l}\text { Two channels originating from two distinct foramina, } \\
\text { and then joining to form a single, broad mandibular } \\
\text { canal }\end{array}$ \\
\hline
\end{tabular}


root and the mandibular canal bifurcation (the bifurcation touches the third molar root) and

d. absence of third molars.

Data were tabulated and analyzed descriptively.

\section{Results}

The study sample consisted of 75 images (40 women, 53\%, and 35 men, 47\%). The patients' ages ranged between 17 and 83 years; mean age was 48.2 $( \pm 13.17)$ years. Table 2 shows the types of mandibular canal bifurcations found in the study, as follows:

- Type 1 in 54 cases (72.6\%);

- Type 2 in 14 cases (19.3);

- Type 3 in 7 cases (8\%).

There were no bifid mandibular canals of Type 4 (bifurcation originating from two foramina) or Type 2BR (bilateral bifurcation limited to the mandibular rami).

Figures 1 to 4 show representative images of the type of bifurcation found most frequently in the study sample.

Regarding the relationship of bifid mandibular canals to the root of third molars, there were no third molars [class D - $43(57.33 \%)$ cases] in most of the images. Of the images that did have third molars, $16(50 \%)$ cases revealed roots of the third molars in an intimate relationship with bifurcation of the mandibular canal (class C, Figure 5), 10 (31\%) cases showed roots in a close relationship with bifurcation (class B, Figure 6), and 6 (19\%) cases had

Table 2 - Classification of bifid mandibular canals found in the sample analyzed (\%), according to Langlais et al. ${ }^{9}$

\begin{tabular}{c|c|c|c}
\hline Type & Code & Number & Percentage (\%) \\
\hline \multirow{3}{*}{ Type 1 } & 1 & 28 & 37.3 \\
\cline { 2 - 4 } & $1 \mathrm{~B}$ & 26 & 34.6 \\
\hline \multirow{4}{*}{ Type 2 } & 2 UR & 1 & 1.3 \\
\cline { 2 - 4 } & 2 UC & 11 & 14.10 \\
\cline { 2 - 4 } & $2 \mathrm{BR}$ & 0 & 0 \\
\cline { 2 - 4 } & $2 \mathrm{BC}$ & 2 & 2.6 \\
\hline Type 3 & - & 7 & 9.3 \\
\hline Type 4 & - & 0 & 0 \\
\hline
\end{tabular}

no involvement of third molar roots with bifurcation of the mandibular canal.

\section{Discussion}

Anatomical knowledge is imperative in dentistry. Variations of normal and/or pathological conditions should be properly diagnosed..$^{16,17}$

Diagnostic errors in interpreting a bifid mandibular canal in a panoramic radiograph may be attributed to superimposition of structures, inadequate positioning of the patient, bone condensation produced by the mylohyoid muscle in the floor of the mouth, distortion of the radiography and magnification of the device. ${ }^{18}$

According to a panoramic radiograph, ${ }^{19}$ the mylohyoid groove anatomy, which frequently forms a bony canal and which sometimes starts from the mandibular canal, could mimic bifurcation. ${ }^{20}$ However, an analysis made with CBCT images would not be interpreted in this way, since the bifurcation may be visualized in different spatial planes (axial, coronal or sagittal) and also in transaxial or oblique slices formed from an outline of the axial cut and subsequent transversal cuts, such as those performed in this study.

CBCT scans provide clearer images of the mandibular canal when compared to digital panoramic radiographs, since $\mathrm{CBCT}$ images are free of overlap and other problems inherent to panoramic radiographs. ${ }^{21}$ Therefore, CBCT should be indicated for surgical planning, to minimize the risk of misinterpretation of the panoramic radiograph.

It is a consensus that the mandibular canal is an anatomical structure of extreme importance for clinical practice, and the recognition of its location is entirely responsible for determining the success of surgical procedures involving the mandible. ${ }^{8,9,22} \mathrm{Al}$ though many studies cited the canal as a single bilateral structure, there are several reports in the literature that clearly demonstrate the presence of a second or even a third accessory mandibular canal. $., 9,13,14,23-26$

The first published studies reported that the incidence of bifid mandibular canals in panoramic radiographs was $1 \% .8,9$ These studies evaluated the presence of bifid mandibular canals using panoramic radiographs. However, more recent studies pointed to a broad variation of the incidence, ran- 
Figure 1 - Unilateral bifurcation (right side) extending to the region of the third molar and adjacent structures (Type 1U). Axial cut (A), lateral (B) and panoramic $(\mathbf{C})$ views. The white arrows indicate the bifurcation and the black arrow indicates the mandibular canal.

\section{$\mathbf{A}$}
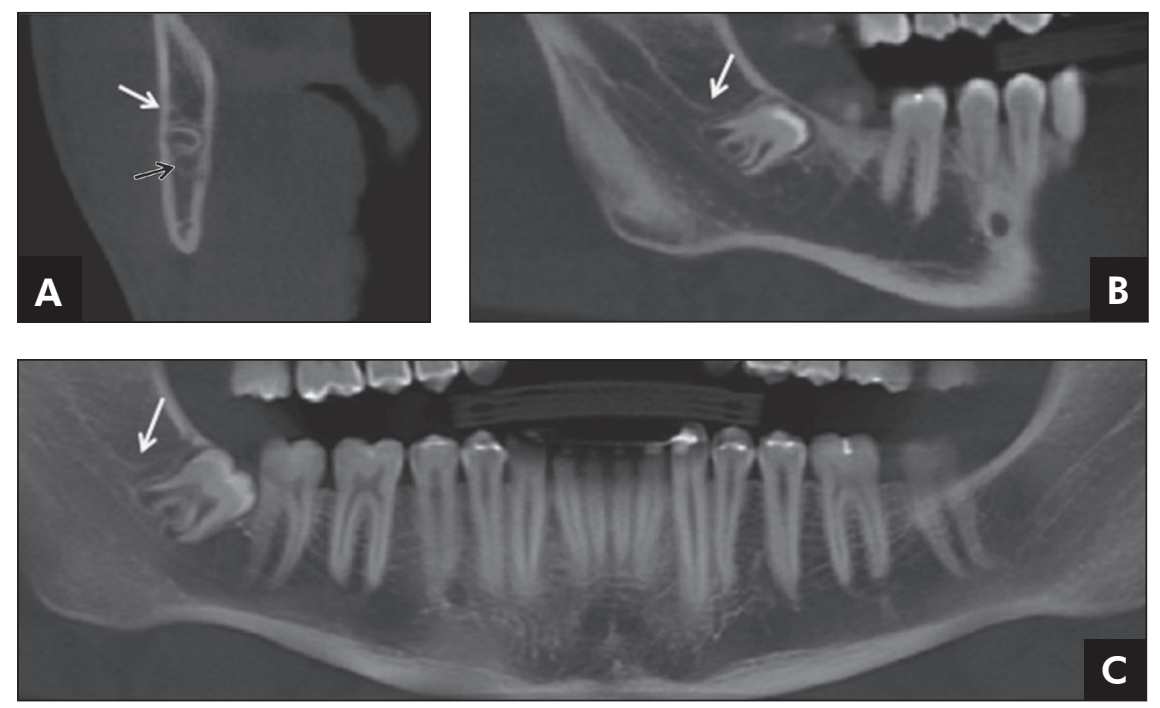

Figure 2 - Bilateral bifurcation extending to the region of the third molar and adjacencies (Type 1B).

Right $(\mathbf{A})$ and left (B) lateral and panoramic $(\mathbf{C})$ views. The white arrows indicate the mandibular canal bifurcation.
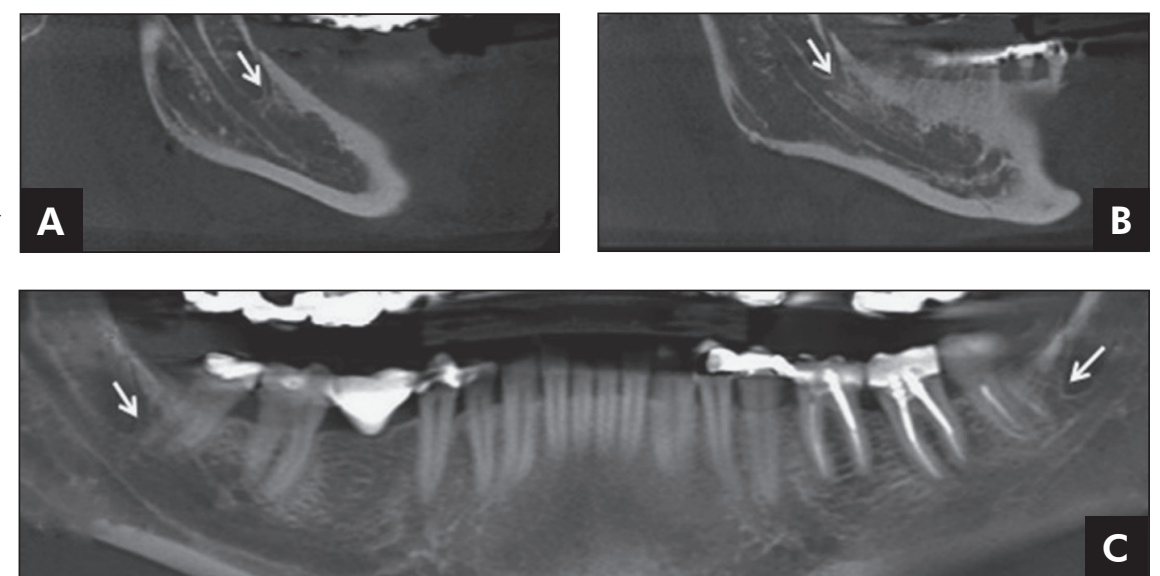

Figure 3 - Unilateral bifurcation (left side) extending along the main canal and united again in the mandibular body (Type 2UC). Left axial cut (A), lateral (B) and panoramic $(\mathbf{C})$ views. The white arrows indicate the bifurcation and the black arrow indicates the mandibular canal.
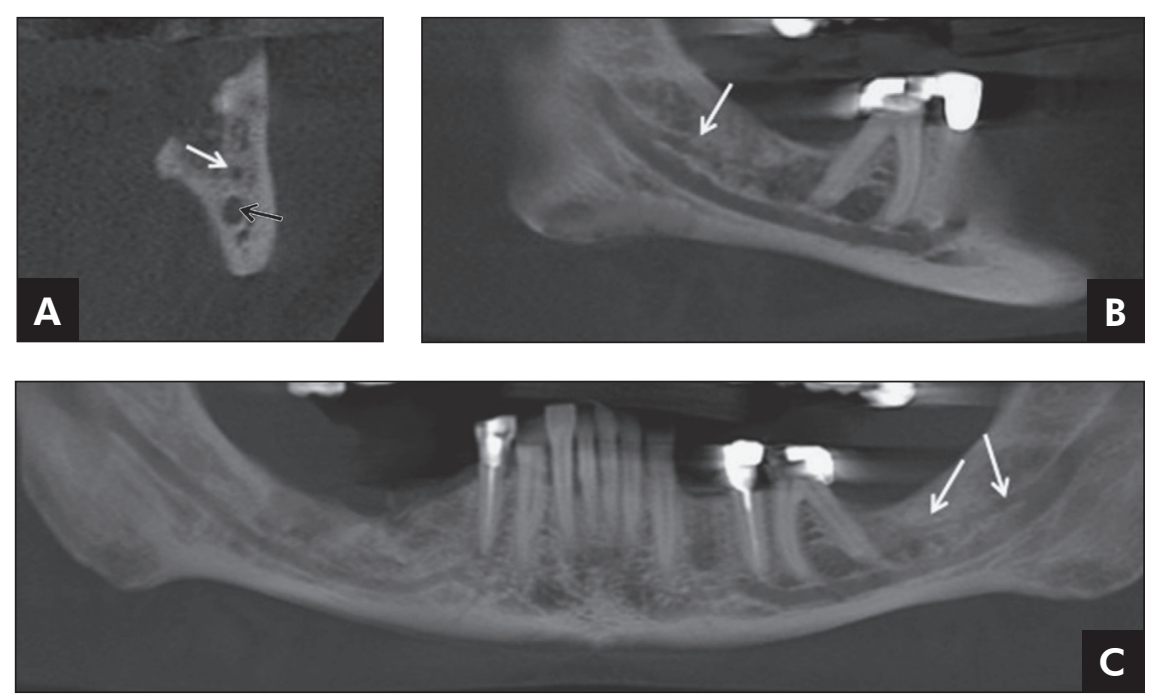
Figure 4 - Combination of the first two categories (Type 3). Right axial cut (A) and lateral view $(\mathbf{B})$ of the bifurcation extending through the mandibular body (Type 2). Bilateral bifurcations in panoramic view $(\mathbf{C})$. Left axial cut (D) and lateral view $(\mathbf{E})$ of the bifurcation, limited to the rami (Type 1). The white arrows indicate the bifurcations of the mandibular canal and the black arrow indicates the mandibular canal.
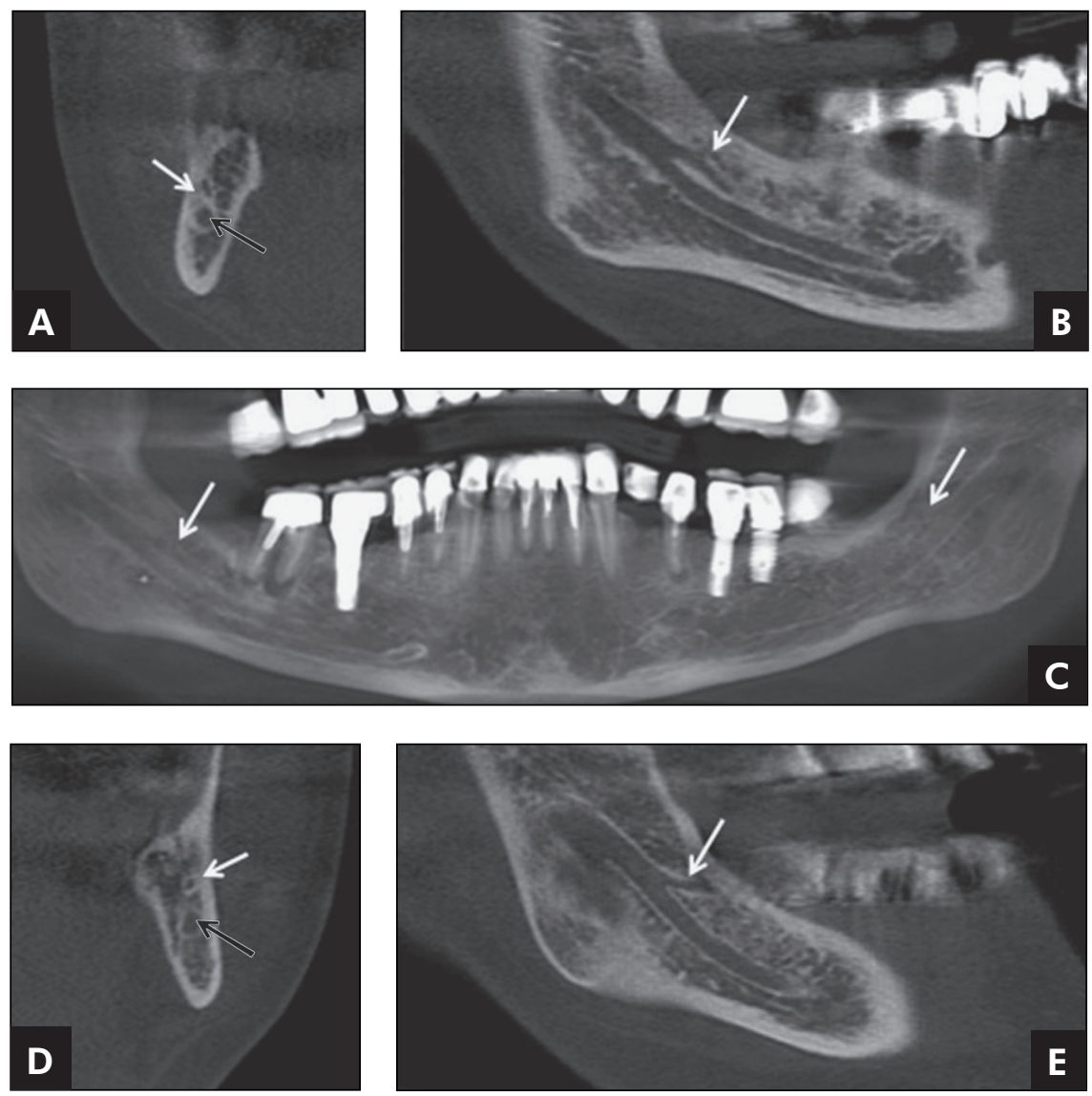

Figure 5 - Different sagittal cuts of Type 1 mandibular canal bifurcation in intimate relationship with impacted left mandibular third molars. The red lines

(light gray in print version) trace the mandibular canal and its bifurcation paths.
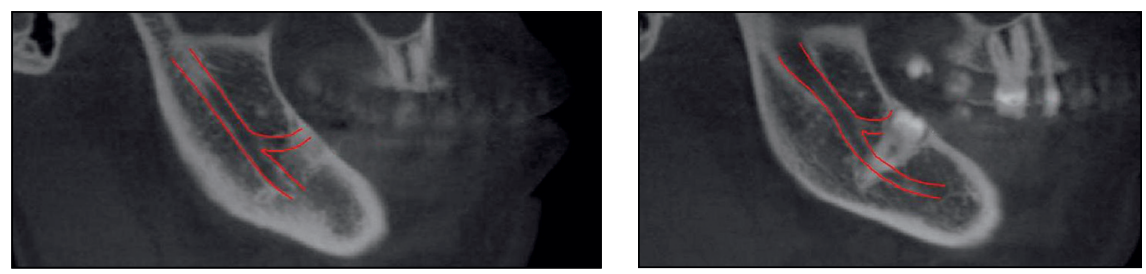

Figure 6 - Transaxial cuts of Type 1 mandibular canal bifurcation close to the roots of the left mandibular third molar. The white arrow indicates the bifurcation and the black arrow, the mandibular canal. The asterisk (*) indicates the third molar roots.

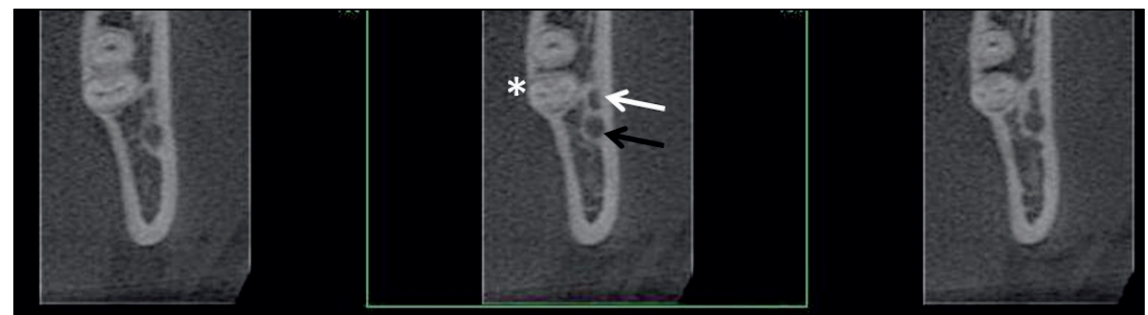

ging from $0.09 \%$ to $36 \% .^{10,11,24}$

This variation in incidence is due to differences in the sample size of each study, as well as to the type of examination performed. Studies carried out using panoramic images show a lower incidence than studies with CBCT images or dry mandibles. ${ }^{18,24,26}$

It is clear that with the advances in technology and the improvement of images as diagnostic tools, 
the number of anatomical variations of the mandibular canal is likely to increase considerably. Naitoh et al. ${ }^{13}$ observed $65 \%$ of bifurcations of the mandibular canal in 122 CBCT scans. On the other hand, Kuribayashi et al. ${ }^{14}$ observed $15 \%$ of bifurcated canals in 301 sides of the mandible, using computed tomography. Since this research work is a retrospective analysis using CBCT previously diagnosed with bifurcations and using a relatively small sample, data could not be obtained on the incidence of bifurcations. These data in our population are still being collected for future comparisons of CBCT images.

Studies have found a higher prevalence of bifid mandibular canals in females, ${ }^{9,13,14}$ as observed in this sample. However, the gender difference was not statistically significant. A recent study ${ }^{15}$ found a higher prevalence of bifurcation in males, in the Taiwanese population. This study was carried out using medical CT. However, the gender differences could be more related to the population observed rather than to the type of exam.

In the CBCT scans of this study, the bifid mandibular canals were classified into four types according to the Langlais et al. ${ }^{9}$ classification. Other classifications have been proposed by Nortjé et al. ${ }^{8}$ and Naitoh et al. ${ }^{13}$ The Langlais classification was chosen because it is still the most cited in the literature on bifurcation of the mandibular canal..$^{10,11}$

The most frequent mandibular canal bifurcation was Type I (72.7\%), which is in agreement with the findings of other studies, ${ }^{15,16}$ but our frequency percentage was higher. Rossi et al. ${ }^{11}$ reported a frequency of Type II mandibular canal bifurcation of $23.3 \%$, which is close to our findings. Nevertheless, Type 2 mandibular canal bifurcation was the most frequent type referred to by Langlais et al. ${ }^{9}$ The largest discrepancy observed in bifid mandibular canal types found in this study was Type III, accounting for only $8 \%$ of the cases, and differing from the findings of other studies, which range from $0 \%$ to $3.92 \%$. No Type IV mandibular canal bifurcation was found in this study. Withal Rossi et al. ${ }^{11}$ reported a high rate $(34.9 \%)$ of this type of mandibular canal bifurcation. Sample characteristics may explain these discrepancies between the incidences of bifurcation types.
Bifid mandibular canals may have important clinical implications. . $7,14,18,27,28$ Third molar surgery with mandibular canal bifurcation involvement may cause excessive bleeding and/or numbness, especially in cases of Type I or III. ${ }^{9}$ Inadequate anesthesia may occur, especially in cases of bifurcation of Type IV, which have two separate foramina. ${ }^{29}$

Bifurcations in the mandibular body may cause complications in procedures such as endodontics. ${ }^{2}$ They may influence prosthesis support, orthodontics ${ }^{16,17}$ and insertion of dental implants. ${ }^{17}$ In surgical procedures, such as mandibular osteotomy, surgery complexity increases with the addition of a second vascular-nerve bundle. Furthermore, in cases of orofacial trauma, the reduction of mandibular fractures must be performed more carefully when there is mandibular canal bifurcation. ${ }^{7}$ If injured, mandibular canal and/or bifurcation may cause bleeding and compromise repair in the implant area.

In regard to third molar roots, most of the sample $(57.33 \%)$ did not show the presence of teeth 38 and/or 48, a fact probably due to the patients' age and the possibility of these teeth having already been extracted.

The incidence of intimate contact of third molar roots with mandibular canal bifurcation was high $(21.33 \%)$, followed by proximal contact of third molar roots with the bifurcation (13.33\%), and only $8 \%$ of cases where the bifid mandibular canal had no involvement with the roots of the third molars, indicating the importance of knowledge and identification of this variation. ${ }^{30}$

Knowledge of both the anatomy and the anatomical variations of the mandibular canal are essential to the success of mandible-related dental procedures. It is important that these variations be identified to prevent treatment complications. The CBCT provides a suitable tool for investigating, identifying and confirming such variations.

\section{Conclusion}

In our study, most bifurcations were unilateral, extending into the region of the third molar or adjacencies (Type 1). When there were third molars, most cases showed an intimate relationship between their roots and mandibular canal bifurcation. 


\section{References}

1. Carter RB, Keen EN. The intramandibular course of the inferior alveolar nerve. J Anat. 1971 Apr;108(3):433-40.

2. Moiseiwitsch JRD.. Position of the mental foramen in a North American, white population. Oral Surg Oral Med Oral Pathol Oral Radiol Endod. 1998 Apr;85(4):457-60.

3. Wadu SG, Penhall B, Towsend GC. Morphological variability of the human inferior alveolar nerve. Clin Anat. 1997 Feb;10(2):82-7.

4. Nikzad S, Azari A, Sabouri S. Double mandibular foramina and canal: report a case with interactive CT-based planning software. Iran J Radiol. 2008 Feb;5(2):83-6.

5. Iizuka T, Lindqvist C. Sensory disturbances associated with rigid internal fixation of mandibular fractures. J Oral Maxillofac Surg. 1991 Dec;49(12):1264-8.

6. Teerijoki-Oksa T, Jääskeläinen SK, Forssel K, Forssel H, Vähätalo K, Tammisalo T, et al. Risk factors of nerve injury during mandibular sagital split osteotomy. Int J Oral Maxillofac Surg. 2002 Feb;31(1):33-9.

7. Claeys V, Wackens G. Bifid mandibular canal: literature review and case report. Dentomaxillofac Radiol. 2005 Jan;34(1):55-8.

8. Nortje CJ, Farmen AG, Grotepass FW. Variations in the normal anatomy of the inferior dental (mandibular) canal: a retrospective study of panoramic radiographs from 3612 routine dental patients. Br J Oral Surg. 1977 Jul;15(1):55-63.

9. Langlais RP, Broadus R, Glass BJ. Bifid mandibular canals in panoramic radiographs. J Am Dent Assoc. 1985 Jun;110(6):923-6.

10. Devito KL, Tamburús JR. [Anatomy of the mandibular canal: radiological classification of its variations]. Rev Assoc Paul Cir Dent. 2001 Jul-Aug;55(4):261-6. Portuguese.

11. Rossi PM, Brücker MR, Rockenbach MIB. [Bifid mandibular canals: panoramic radiographic analysis]. Rev Cienc Med. 2009 Mar-Apr;18(2):99-104. Portuguese.

12. Rouas P, Nancy J, Bar D. Identification of double mandibular canals: literature review and three case report with CT scans and cone beam CT. Dentomaxillofac Radiol. 2007 Jan;36(1):34-8.

13. Naitoh M, Hiraiva Y, Aimiya H, Ariji E. Observation of bifid mandibular canal using cone beam computerized tomography. Int J Oral Maxillofac Implants. 2009 Jan-Feb;24(1):155-9.

14. Kuribayashi A, Watanabe H, Imaizumi A, Tantanapornkul W, Katakami K, Kurabayashi T. Bifid mandibular canals: cone beam computed tomography evaluation. Dentomaxillofac Radiol. 2010 May;39(4):235-9.

15. Fu E, Peng M, Chiang CY, Tu HP, Lin YS, Shen EC. Bifid mandibular canals and the factors associated with their presence: a medical computed tomography evaluation in a Taiwanese population. Clin Oral Implants Res. 2012 Nov 6. doi: 10.1111/ clr.12049. Epub ahead of print.

16. al Jasser NM, Nwoku AL. Radiographic study of the mental foramen in a selected Saudi population. Dentomaxillofac Radiol. 1998 Nov;27(6):341-3.
17. de Oliveira-Santos C, Souza PH, De Azambuja Berti-Couto SA, Stinkens L, Moyaert K, Rubira-Bullen IR, et al. Assessment of variations of the mandibular canal through cone beam computed tomography. Clin Oral Investig. 2012 Apr;16(2):387-93.

18. Sanchis JM, Peñarrocha M, Soler F. Bifid mandibular canal. J Oral Maxillofac Surg. 2003 Apr;61(4):422-4.

19. Kim MS, Yoon SJ, Park HW, Kang JH, Yang SY, Moon YH, et al. A false presence of bifid mandibular canals in panoramic radiographs. Dentomaxillofac Radiol. 2011 Oct;40(7):434-8.

20. Arensburg B, Nathan H. Anatomical observation of the mylohyoid groove, and the course of the mylohyoid nerve and vessels. J Oral Surg. 1979 Feb;37(2):93-6.

21. Angelopoulos C, Thomas S, Hechler S, Parissis N, Hlavacek $\mathrm{M}$. Comparison between digital panoramic radiography and cone-beam computed tomography for the identification of the mandibular canal as part of presurgical dental implant assessment. J Oral Maxillofac Surg. 2008 Oct;66(10):2130-5.

22. Xie Q, Wolf J, Soikkonen K, Ainamo A. Height of mandibular basal bone in dentate and edentulous subjects. Acta Odontol Scand. 1996 Dec;54(6):379-83.

23. Auluck A, Pai KM, Shetty C. Pseudo bifid mandibular canal. Dentomaxillofac Radiol. 2005 Nov;34(6):387-8.

24. Bogdan S, Pataky L, Barabas J, Nemeth Z, Huszar T, Szabo G. Atypical courses of the mandibular canal: comparative examination of dry mandibles and x-ray. J Craniofac Surg. 2006 May;17(3):487-91.

25. Wadhawani P, Mathur RM, Kohli M, Sahu R. Mandibular canal variant: a case report. J Oral Pathol Med. 2008 Feb;37(2):122-4.

26. Fukami K, Shiozaki K, Mishima A, Kuribayashi A, Hamada Y, Kobayashi K. Bifid mandibular canal: confirmation of limited cone beam computed tomography findings by gross anatomical and histological investigations. Dentomaxillofac Radiol. 2012 Sep;41(6):460-5.

27. Lew K, Townsend G. Failure to obtain adequate anaesthesia associated with a bifid mandibular canal: a case report. Aust Dent J. 2006 Mar;51(1):86-90.

28. Mizbah K, Gerlak N, Maal TJ, Bergé SJ, Meijer GJ. The clinical relevance of bifid and trifid mandibulars canals. Oral Maxillofac Surg. 2012 Mar;16(1):147-51.

29. DeSantis JL, Liebow C. Four common mandibular nerve anomalies that lead to local anesthesia failures. J Am Dent Assoc. 1996 Jul;127(7):1081-6.

30. Tantanapornkul W, Okouchi K, Yoshikuni F, Yamashiro M, Maruoka Y, Ohbayashi N, et al. A comparative study of conebeam computed tomography and conventional panoramic radiography in assessing the topographic relationship between the mandibular canal and impacted third molars. Oral Surg Oral Med Oral Pathol Oral Radiol Endod. 2007 Feb;103(2):253-9. 